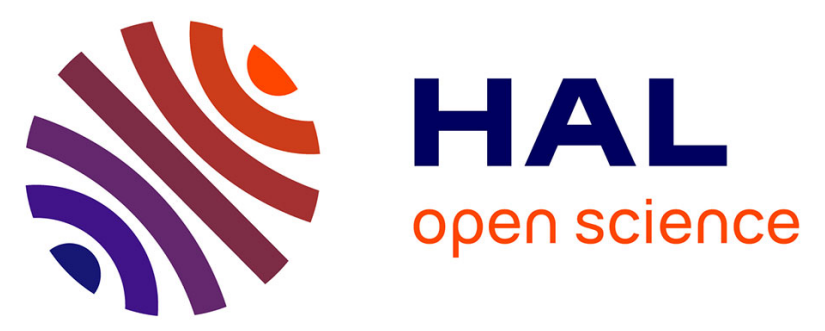

\title{
Adverse drug reactions in internal medicine units and associated risk factors
}

Juan Francisco Sánchez Muñoz-Torrero, Paloma Barquilla, Raul Velasco, Maria del Carmen Fernández Capitan, Nazaret Pacheco, Lucia Vicente, Jose Luis Chicón, Sara Trejo, Jose Zamorano, Alicia Lorenzo Hernandez

\section{To cite this version:}

Juan Francisco Sánchez Muñoz-Torrero, Paloma Barquilla, Raul Velasco, Maria del Carmen Fernández Capitan, Nazaret Pacheco, et al.. Adverse drug reactions in internal medicine units and associated risk factors. European Journal of Clinical Pharmacology, 2010, 66 (12), pp.1257-1264. 10.1007/s00228010-0866-6 . hal-00613747

\section{HAL Id: hal-00613747 https://hal.science/hal-00613747}

Submitted on 6 Aug 2011

HAL is a multi-disciplinary open access archive for the deposit and dissemination of scientific research documents, whether they are published or not. The documents may come from teaching and research institutions in France or abroad, or from public or private research centers.
L'archive ouverte pluridisciplinaire HAL, est destinée au dépôt et à la diffusion de documents scientifiques de niveau recherche, publiés ou non, émanant des établissements d'enseignement et de recherche français ou étrangers, des laboratoires publics ou privés. 


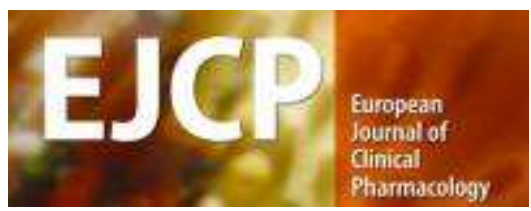

\section{Adverse drug reactions in Internal Medicine Units, and risk factors associated}

\begin{tabular}{|c|c|}
\hline Journal: & European Journal of Clinical Pharmacology \\
\hline Manuscript ID: & EJCP-2010-0140.R1 \\
\hline Type of submission: & Original \\
\hline $\begin{array}{r}\text { Date Submitted by the } \\
\text { Author: }\end{array}$ & 12-Jun-2010 \\
\hline Complete List of Authors: & $\begin{array}{l}\text { Sánchez Muñoz-Torrero, Juan Francisco; H.San Pedro Alcántara, } \\
\text { Internal Medicine } \\
\text { Barquilla, Paloma; H. San Pedro Alcantara, Internal Medicine } \\
\text { Velasco, Raul; H. San Pedro Alcantara, Internal Medicine } \\
\text { Fernandez Capitan, Maria del Carmen; H. La Paz, Internal Medicine } \\
\text { Pacheco, Nararet; H. San Pedro Alcantara, Internal Medicine } \\
\text { Vicente, Lucia; H. San Pedro Alcantara, Internal Medicine } \\
\text { Chicón, Jose Luis; H. San Pedro Alcantara, Internal Medicine } \\
\text { Trejo, Sara; H. San Pedro Alcantara, Internal Medicine } \\
\text { Zamorano, Jose; H. San Pedro de Alcantara, Unidad Investigacion } \\
\text { Lorenzo Hernandez, Alicia; H. La Paz, Internal Medicine }\end{array}$ \\
\hline
\end{tabular}

\section{今 scholarONE" \\ Manuscript Central}


Adverse drug reactions in Internal Medicine Units, and risk factors associated.

Juan Fco Sánchez Muñoz-Torrero. MD, PhD.

Paloma Barquilla. MD..

Raul Velasco. MD.

Carmen Fernández Capitan*. MD, PhD

Nazaret Pacheco. MD.

Lucia Vicente. MD.

Jose Luis Chicón. MD.

Sara Trejo. MD.

Jose Zamorano. Ph.D.

Alicia Lorenzo Hernandez*. MD.

Servicios de Medicina Interna Hospital San Pedro de Alcantara. (Cáceres) and, Hospital La Paz. (Madrid) ${ }^{\star}$

Keywords: Adverse drug reactions, incidence, risk factors.

Word count (abstract) : 243

Word count article (excluding abstract, references, tables) : 2454

Correspondence should be addressed to:

Juan Fco Sánchez Muñoz-Torrero, MD, Ph D

Servicio de Medicina Interna

Hospital San Pedro de Alcantara.

10004 Cáceres. Spain

e-mail: juanf.sanchezm@gmail.com 


\begin{abstract}
Objetives: This study was designed to assess the prevalence of adverse drug reactions (ADRs) in Internal Medicine wards of two teaching Hospitals, identify the most common ADRs, principal medications involved and, determine the risk factors implicated in the appearance of such ADRs. Methods: All admissions over 10-weeks were followed prospectively using an intensive drug surveillance method to identify ADRs. Clinical, laboratory data, drug prescribed and ADRs were taken into consideration. Status of nutrition, liver and kidney function at admission and ADRs time were determined. In order to assess drugs interaction a software package was used. Results: A total of 405 patients were evaluated, 126 patients (31\%) had 128 ADRs, 122 ADRs occurred during hospitalization. Two ADRs-related deaths were observed during the study. Reactions affecting the gastrointestinal tract, skin and haematological system were among the most frequently ADRs. For ADRs observed during admission predictors of its occurrence in a multivariable regression model were: OR $(95 \% \mathrm{CI})$; more 12-days hospitalization: $2.11(1.27-3.47)$, any drug interaction: 9.33 (5.12-17) and acute change estimated glomerular filtration rate over admission $>20 \%: 2.46(1.45-4.2)$. Worsening of renal function or drug interaction was observed in nine of ten ADRs. Age, sex, nutrition and number of drugs used were not related with ADRs. Conclusion: A significant prevalence of ADRs was found among hospitalized patients. Duration of hospital admission, changes in renal status during hospitalization and drugs interaction seem to be important risk factors to ADRs.
\end{abstract}




\section{Introduction.}

Adverse drug reactions (ADRs) are a major cause of morbidity and pose a substantial burden on healthcare resources ${ }^{1}$. Detection of adverse drug reactions in hospitals provides an important measure of the burden of drug-related morbidity on the healthcare system. Epidemiological research shows an incidence of ADRs in 10-13\% of all hospitalized patients ${ }^{1-3}$. These data remain clinically relevant because a significant proportion of ADRs are lifethreatening or fatal ADRs, rank fourth to sixth in leading causes of death 4,5 . Because up to $50 \%$ of $A D R$ are preventable more attention to their detection and management is warranted ${ }^{6,7}$.

Previous studies explored magnitude, nature and prevalence of ADRs. Common factors associated with ADRs are age, sex, number of drugs or comorbidities ${ }^{5-10}$. Meanwhile, other important factors such as renal function or pharmacologic counteractions, have not been well studied $^{1-12}$. Patients hospitalized in Internal Medicine wards have predisposition of suffering ADRs because they are older, have several comorbidities, and need multiple drugs at hospitalization. So patients hospitalized at Internal Medicine wards stand for an interesting population for studying $A D R s^{11}$. Frequently these patients have renal insufficiency that can worse during hospitalization because of the disease or condition that is causing the hospitalization. The different interactions between drugs could be also an important issue in the apparition of $A D R S^{12}$. Due to the complexity of treatments and the large number of drugs required, the clinician may not consider the interactions between drugs in daily practice. Recently several software package have show useful for analyzer drug prescription that can be useful for predicting drug interactions and so, adjust treatments easier ${ }^{12,13 .}$

The aim of this study was to describe the most common clinical manifestations and drugs frequently responsible for ADRS and, to identify in patients who had ADRs while they were hospitalized in internal medicine independent factors predictive of these ADRS including drugs interaction and acute changes in renal function. 
PATIENTS AND METHODS. This prospective observational study included all patients admitted in two General Internal Medicine wards of 2 Docents Hospitals, San Pedro de Alcantara (Cáceres) and La Paz (Madrid) in Spain, over a period of 10 consecutive weeks from 1 September 2009 to 14 November 2009. For detection and evaluation of potential ADRS all admissions underwent daily intensive pharmacovigilance by at minimum three physicians (1 staff physician and 2 residents in training). Classification of adverse drug reactions. The classification proposed by Rawlins and Thompson ${ }^{14}$ was used to establish the potential for predicting suspected adverse reactions. The algorithm of Naranjo ${ }^{15}$ and co-workers was used to establish the causality between the drug and the suspected adverse reaction. ADR was considered if it was definitive or probable.Data were collected using a specific data collection sheet developed for this investigation. For all patients, information regarding age, sex, weight and tall, duration of hospital stay, all diagnosis at discharge was collected, as well as amounts and brand names of medicines taken in the previous month, during the hospitalization, including self -medication. Blood test for creatinina, ALT, AST, alkaline fosfatase and filtration glomerular rate (estimated by Cockroft-Gault formula:GFR(ml/min) $=(140$-age $(\mathrm{y})) \times$ body weight $(\mathrm{kg}) / 72 \mathrm{x}$ serum creatinine $(\mathrm{mg} / \mathrm{dl})$; in female $\times 0.85)$ ) were determinate at entry and the day of detection of ADRs. Patients were then classified into (Group 1) patients without ADR, (Group 2) patients admitted because of ADR or detected during hospitalization.

The possible interactions between drugs were evaluated using Lexi-Interact ${ }^{\mathrm{TM}}$ Online (LexiComp, Inc. Ohio ${ }^{16}$. This is a comprehensive Drug-to-Drug Interaction Analysis Program with a Rapid indicator to show the interaction data. This program also assigned a risk rating of $A, B, C$, $\mathrm{D}$, or $\mathrm{X}$. The progression from $\mathrm{A}$ to $\mathrm{X}$ is accompanied by increased urgency for responding to the data. In general, A and B monographs are of academic, but not clinical concern. Monographs rated $\mathrm{C}, \mathrm{D}$, or $\mathrm{X}$ always requires the user's attention. The definition of each risk rating is as follows: A: No Known Interaction, B: Data demonstrate that the specified agents may interact with each other, but there is little to no evidence of clinical concern resulting from their concomitant use. No Action Needed. C: Data demonstrate that the specified agents may 
interact with each other in a clinically significant manner. The benefits of concomitant use of these two medications usually outweigh the risks. An appropriate monitoring plan should be implemented to identify potential negative effects. Dosage adjustments of one or both agents may be needed in a minority of patients. Monitor Therapy. D: Data demonstrate that the two medications may interact with each other in a clinically significant manner. A patient-specific assessment must be conducted to determine whether the benefits of concomitant therapy outweight the risks. Specific actions must be taken in order to realize the benefits and/or minimize the toxicity resulting from concomitant use of the agents. These actions may include aggressive monitoring, empiric dosage changes, choosing alternative agents. Consider Therapy Modification. $X$ : Data demonstrate that the specified agents may interact with each other in a clinically significant manner. The risks associated with concomitant use of these agents usually outweigh the benefits. These agents are generally considered contraindicated. Avoid Combination. The severity of ADRS was defined as: Minor (effects would be considered tolerable; in most cases no need for medical intervention); Moderate (medical intervention needed to treat effects; effects do not meet criteria for Major); and Major (effects may result in death, hospitalization, permanent injury, or therapeutic failure). We also collected about the need of prolong hospitalization and the drug interaction itself as the cause of hospitalization.

Data analysis. All the data were expressed as the mean \pm SD or percentage. The differences in the values of the variables between the start and the end of the 10 -weeks treatment period were calculated as percent changes, values at the end of 12 week's treatment minus those at the start of the treatment $\times 100 /$ the value at the start of the treatment. Patients who were hospitalized because of ADRS were excluded for the study of potential factors associated with ADRS. The Chi-square test and Student's t-test for independent samples were used to assess the statistical significance between ratios and means, respectively. In order to control potential confounding factors and to determine independent association between ADRS and risk factors for ADRS, the logistic regression analysis was employed. Factors demonstrating significant association with an ADR were included in the multivariable logistic regression model. Since 
other researchers had identified sex and age as risk factors for an ADR, these variables were included in the model without considering the statistical significance of the univariate analysis. A $p$ value lower to 0.05 was considered statistically significant. Data analysis was performed using the SPSS software package (SPSS Inc., Chicago, Illinois, USA).

Results: During a 10-weeks study period in two university hospitals, 405 patients were intensively monitored with respect to ADRs. (Fig.1). There were 128 adverse reactions in 126 (31\%) patients. In 24 patients the ADRs was the cause of hospitalization and 102 patients suffered ADRs during the hospitalization in internal medicine ward. The ADRs were moderate in $93(73 \%)$, major in $22(17 \%)$ and were fatal in 2 patients $(1,6 \%)$.

Table 1 shows main characteristics of patients in the study. There were no significant differences between the group of ADRs and non ADRs in age, sex and BMI. Number of diagnoses of each patient was bigger in patients with ADRs: $2,3 \pm 1.2$ vs. $2.0 \pm 1.1$. ADRs patients have more lung diseases $(35 \%$ vs. $25 \%, p<0.05)$ and diabetes than controls $(35 \%$ vs. $20 \%, p<0.001)$. An important difference was the duration of hospitalization that was longer for ADRs patients: $18 \pm 17$ days vs. $9.6 \pm 5.8, p<0.001$. Time from hospitalization to ADRs was $4.3 \pm 3.9$ days.

Table 2 shows the drugs causing the different ADRs. 28 patients suffered from diarrhea because of antibiotic use. The second most frequent ADRs was bleeding, because of acenocumarol or enoxaparin (15 patients). The third frequent ADRs was rash (9 patients), although cutaneous involvement was the ADRs in 20 patients, mainly due to some antibiotics but also fenitoin and atorvastatin.

Among patients who had ADRs during admission, (were excluded from analysis those hospitalized for this reason), factors associated with the aparition of ADRs were analyzed and showed in table 3. Renal function and drug-drug interaction were statiscally significative $(p<$ 0.001). Elevated serum creatinine at hospitalization was significantly higher in patients at ADRs than more high in control group during hospitalization $(\mathrm{mg} / \mathrm{dL}): 2.02 \pm 1.22 \mathrm{vs} 1.72 \pm 0.95$. A filtration glomerular rate below of $60 \mathrm{ml} / \mathrm{min}$ was observed in $41 \%$ of patients with ADRs vs $22 \%$ 
in control. A decreased of filtration glomerular rate of $20 \%$ respect a baseline during hospitalization appeared in $35 \%$ of case patients and $18 \%$ of controls $(p<0.001)$. Possible interaction between drugs was analyzed by an electronic device and were found in $84 \%$ patients with ADRs vs. $36 \%$ controls $(p<0.0001)$ Drugs causing interactions were metabolized mainly by cytochrome P 450 2C9 (drugs behave as inhibitors and substrates), 3A4 (inducers) and 2D6 (substrates). Interaction between three or more drugs appeared in $35 \%$ of ADRs patients and $15 \%$ controls $(p<0.001)$. We judged as cause ADRs: 41 drugs interaction, decrease in renal function in 28 patients, and 17 possible influence of both. The Drug interactions are most likely involved were: 21 patients cytochrome P 450 (2C9), 8 ( 3A4), 6(2D6), 4(1A2), 1(2C9) and 1 (2C19).

In the logistic regression analysis to analyze factors associated with ADRs we found (as shown in table 4): the duration of hospitalization $(p<0.001)$, change of $20 \%$ of filtration glomerular rate $(p<0.001)$ and any drug interaction were associated with ADR $(p<0.0001)$.

\section{Discussion:}

The most common ADRs in hospitalized patients and factors associated were analyzed in this study. Diarrhea postantibiotic, bleeding due to antithrombotic therapy and rash were the most frequent ADRs observed. Conditions associated with ADRs during hospitalization were prolonged hospitalization, acute change in filtration glomerular rate and drug interaction. Other previously cited as risk factors, like age, sex and number of drugs used were not related with ADRs in our study.

The frequency of ADRs in hospitals varies greatly between different published studies ${ }^{2-4}$, which can be explained by differences in their methods of identifying ADRs, the definition of adverse reactions, the methodology used for their detection, the complexity level of the pathologies under treatment and the severity of the reaction, among others 5,8,9,11,12,17-19. The rate of ADRs found in this study $-31 \%$ - was higher than the average of $6.7 \%$ (range $1.2-24 \%$ ) found in previous studies ${ }^{2-4}$ but consistent with other reports 20,21 using, like us, the "gold standard of 
pharmacovigilance", intensive prospective ADRs detection ${ }^{20-21}$. Drugs causing ADRs ${ }^{23}$ were similar to those described by other authors $16,21,23$ where cardiovascular drugs, anticoagulants and antibiotics were most frequently associated with ADRs. Reactions affecting the gastrointestinal tract, skin, mucosa and haematological system are among the most frequently observed events. The ADRs are in relation with drugs used for managing frequently disease of patients admitted in Internal Medicine wards.

Previous studies have examined many potential risk factors associated with ADRs in a variety of settings $5,7,10$. Conditions often cited as potential risk factors of ADRs are increasing age, sex, large numbers of prescribed drugs in individual patients or length of hospitalisation ${ }^{5-10}$. Failure of dose adjustment in patients with impaired renal function and, drug-drug interactions also were as important predictors of ADRs ${ }^{10-12}$. Studies in the field of pharmacovigilance using multiple regression models are rare and, we unknown what variables were independent ADR predictors $^{20}$. There is consensus about the predictive power of large numbers of prescribed drugs -more than four- as an independent predictor of ADRs ${ }^{6,8,20}$. In our analysis, number of drug interactions were one of the most important factors associated with apparition of ADRs, but not the number of drugs itself. We found a high rate of medication use with interaction by cytocrome P450 2C9,2D6 and 3A4. These cytocrome frequently are implicate in metabolism of common drugs ${ }^{25}$. Nowadays, complexity of treatments make difficult to know the possibility of apparition of interactions between two or more drugs, so adequate software package ${ }^{25-27}$ will be useful in this way. Most studies summarized that $69 \%$ of adverse events as preventable ${ }^{7,23}$ and can therefore be considered to result from medication errors. Although they are several recommendations about using electronic devices, their use have not been generalized and electronic devices have several problems that have to be removed ${ }^{25,27}$. We suggest checking drug interactions on a software package, or assess the cytocrome involve in metabolism of drugs most frequently .

Other common problem that has not been previously well studied is renal function as cause of ADRS 27,30. We report an elevated incidence of renal dysfunction measured as having 
glomerular filtration rate below $60 \mathrm{ml} / \mathrm{min}, 41 \%$ in ADRS patients vs $22 \%$ controls. Also we observe a worsening of renal function during hospitalization, renal function drop $>20 \%$ in $35 \%$ of case vs $18 \%$ controls. This important prevalence of renal impairment was clearly different from reported by others ${ }^{27}$.Dose adjustment with renal function probably would have prevented the apparition of several ADRs. Although, we can observe ADRs before identify the changes in renal function, prevent dose titration. Sex, age and malnutrition were also correlated with the presence of ADRs in literature reports ${ }^{5-10}$. However, in our population, neither albumin, sex or increasing age were independent ADR predictors. In summary, acute changes in renal function or drug interactions were observed in $88 \%$ of patients suffering ADRs. Therefore we suggest that drug doses adjustment for renal function and assess interactions could be prevenible a great number of ADRs in clinical practice.

In terms of pharmacoeconomy it was calculated that cost of hospitalization of patient with ADRs could be about two thousand of million dollars per year in the United States ${ }^{30}$. It is estimated that patients who had an adverse drug reaction, the duration of hospitalization was prolonged by 4,3 days compared with patients who did not experience an adverse drug reaction leading to an increase in costs for each episode of hospitalization. In the present study, lenght of hospitalization was greater for ADRS (18 vs 9,6 days). We can't analyze if a longer duration was the cause or the consequence of ADRs. However, the fact that ADRs appeared in the 5 day of hospitalization in most cases, shows that ADRs can be one of the main causes of a longer duration of being hospitalized for ADRs patients.

The study have some limitations. Probably the most important is the fact that we couldn't analyzed specifically the factor implicated in ADRs in each particular case. Despite using a multiple regression model, a definitive discrimination between causative or confounding factors in predicting an ADR is difficulty. We can not judge if renal failure was cause or effect of ADRs in all situations. Also, we only analysed pharmacokinetic and no pharmacodynamic interactions due of program used. However, renal insufficiency or drug interaction were implicated in nine of 
ten ADRs, so we have to consider these two mechanisms as very important factors contributing to ADRs development. Studies with a longer period of observation and more hospitals implicated in the study of ADRs would help to determine the significance of these mechanisms in ADRs or identifying more factors implicated.

In summary, we believe that the present study makes important contributions. First, the real incidence of ADRs in Internal Medicine could have been infraestimated. Second, acute renal function worsening during hospitalization, prior renal dysfunction and drug interactions seem to be important factors contributing to ADRs appearance.

\section{References:}

1. Kohn LT, Corrigan JM, Donaldson MS, Editors.Institute of Medicine. To error is human: building a safer health system. Washington, DC. National Academies Press, 2000

2. Pirmohamed M, Breckenridge AM, Kitteringham NR, Park BK. Adverse drug reaction. BMJ 1998; 316: 1295-1298.

3.Davies EC, Green CF, Mottram DR, Pirmohamed M. Adverse drug reactions in hospitals: a narrative review. Curr Drug Saf. 2007;2:79-87.

4.Trontell A. Expecting the unexpected: drug safety, pharmacovigilance, and the prepared mind. N Engl J Med 2004; 351: 1385-7.

5. Talley RB, Laventurier MF. Drug-induced illness. JAMA 1975; 229:1043-1048

6. Lagnaoui R, Moore N, Fach $\mathrm{J}$ et als. Adverse drug reactions in a department of systemic diseases-oriented internal medicine: prevalence, incidence, direct costs and avoidability. Eur $\mathrm{J}$ Clin Pharmacol. $2000 ; 56: 181-6$.

7. McDonnell PJ, Jacobs MR. Hospital admissions resulting from preventable adverse drug reactions. Ann Pharmacother. 2002;36:1331-6.

8. Klein $\mathrm{U}$, Klein $\mathrm{M}$, Sturm $\mathrm{H}$, et als. The frequency of adverse drug reactions as dependent upon age, sex and duration of hospitalization. Int J Clin Pharmacol Biopharm. 1976;13:187-95.

9. Martin RM, Biswas PN, Freemantle SN, et als Age and sex distribution of suspected adverse drug reactions to newly marketed drugs in general practice in England: analysis of 48 cohort studies. Br J Clin Pharmacol. 1998;46:505-11.

10. Zopf Y, Rabe C, Neubert A, Janson C, Brune K, Hahn EG, Dormann H.

Gender-based differences in drug prescription: relation to adverse drug reactions. 
Pharmacology. 2009;84:333-9.

11. Krähenbühl-Melcher $A$, Schlienger $R$, Lampert $M$, Haschke $M$, Drewe J, Krähenbühl $S$. Drug-related problems in hospitals: a review of the recent literature. Drug Saf. 2007;30:379-407. 12. Schein JR. Epidemiology, outcomes research, and drug interactions Drug Metabol Drug Interact. 1998;14:147-58.

13. Kuperman GJ, Bobb A, Payne TH, et als. Medication-related clinical decision support in computerized provider order entry systems: a review. J Am Med Inform Assoc. 2007;14: 29-40.

14. Rawlins MD, Thompson JW. Mechanisms of adverse drug reactions. In: Davies DM, ed. Textbook of adverse drug reactions. Oxford: Oxford University Press, 1991: 18-45

15. Naranjo CA, Busto $U$ Sellers EM, et al. A method for estimating the probability of adverse drug reactions. Clinical Pharmacology and Therapeutics 1981; 30: 239-245.

16. Lexi-Comp. Drug interactions handbook, and drug interactions software. http://www.lexi.com/web/index.jsp.(Accessed June 10, 2010)

17. Hazell L, Shakir SA. Under-reporting of adverse drug reactions : a systematic review. Drug Saf. 2006;29:385-96.

18. Lazarou J. Pomeranz BH. Corey PN. A Meta-analysis of Prospective Studies Incidence of Adverse Drug Reactions in Hospitalized. JAMA 1998;279:1200-1205.

19. Brvar M, Fokter N, Bunc M, Mozina M. The frequency of adverse drug reaction related admissions according to method of detection, admission urgency and medical department specialty. BMC Clinical Pharmacology 2009, 9:8

20. Zopf $Y$, Rabe C, Neubert A, Hahn EG, Dormann H. Risk factors associated with adverse drug reactions following hospital admission: a prospective analysis of 907 patients in two German university hospitals. Drug Saf. 2008;31:789-98.

21. Camargo AL, Cardoso Ferreira MB, Heineck I. Adverse drug reactions: a cohort study in internal medicine units at a university hospital. Eur J Clin Pharmacol. 2006;62:143-9.

22. Fattinger $K$, Roos $M$, Vergères $P$, et als. Epidemiology of drug exposure and adverse drug reactions in two swiss departments of internal medicine. Br J Clin Pharmacol. 2000;49:158-67 23. Bond CA. Raehl CL. Adverse Drug Reactions in United States Hospitals. Pharmacotherapy, 2006;26:601-608

24. Bates DW, Cullen DJ, Laird N, et als. Incidence of adverse drug events and potential drug events. Implications for prevention. JAMA. 1995;274:29-34.

25. Flockhart, D. A. Drug Interactions and Cytochrome P450 System: The role of Cytochrome P450 2C19. Clin. Pharmacokinet. 1995;29(suppl. 1): 45-52

26. Szekendi MK, Sullivan C, Bobb A et al. Active surveillance using electronic triggers to detect adverse events in hospitalized patients. Qual Saf Health Care 2006;15:184-190.

27. Bobb A, Gleason K, Husch M, et als. The epidemiology of prescribing errors: the potential impact of computerized prescriber order entry. Arch Intern Med. 2004;164:785-92.

28. Helldén $A$, Bergman $U$, von Euler $M$, et als. Adverse drug reactions and impaired renal function in elderly patients admitted to the emergency department: a retrospective study. Drugs Aging. 2009;26:595-606 
29. Verbeeck RK, Musuamba FT. Pharmacokinetics and dosage adjustment in patients with renal dysfunction. Eur J Clin Pharmacol. 2009;65:757-73.

30.Lundkvist J, Jönsson B. Pharmacoeconomics of adverse drug reactions. Fundam Clin Pharmacol. 2004;18:275-80.

Fig 1: Distribution of patients according to presence od adverse drugs reactions (ADRs)

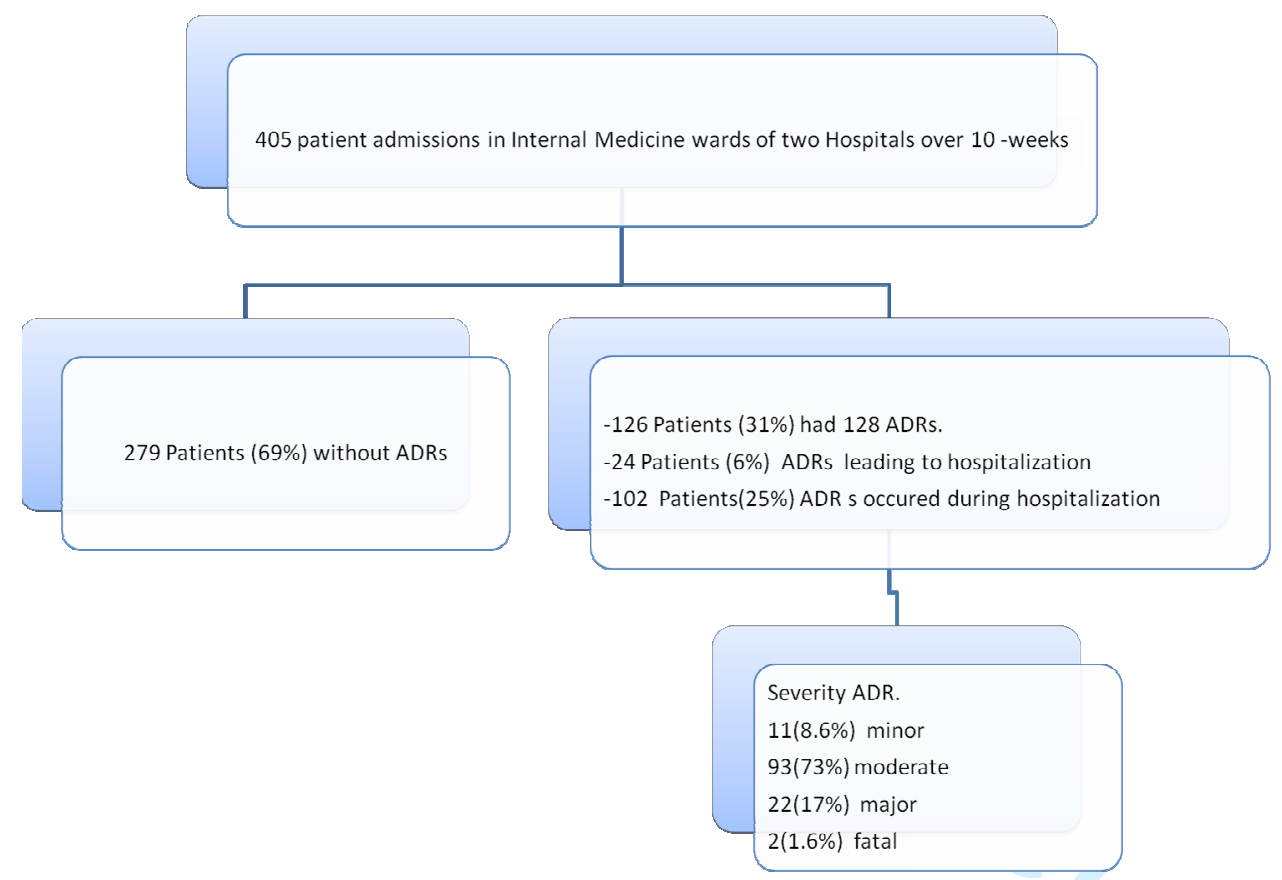


Table 1: Baseline Characteristics of Patients.

\begin{tabular}{|l|c|c|c|}
\hline VARIABLE & $\begin{array}{c}\text { CONTROL } \\
\text { N=279 }\end{array}$ & CASES & N $=126$ \\
\hline & $151(54 \%)$ & $59(47 \%)$ & 0.22 \\
Sex-male & $67(15-102)$ & $69(16-97)$ & 0.3 \\
Age-years: median (range) & $112(40 \%)$ & $53(42 \%)$ & 0.25 \\
Age $>75$ year- $\mathrm{n}(\%)$ & $26 \pm 5$ & $27 \pm 6$ & 0.09 \\
Body Mass Index-Kg/m2 & $2.0 \pm 1.1$ & $2.3 \pm 1.2$ & 0.02 \\
Previous Diagnosis & $98(35 \%)$ & $54(43 \%)$ & 0.1 \\
Chronic Heart Failure & $70(25 \%)$ & $44(35 \%)$ & 0.03 \\
Pulmonary Disorders & $56(20 \%)$ & $44(35 \%)$ & $<0.001$ \\
Diabetes & $64(23 \%)$ & $30(24 \%)$ & 0.4 \\
Cardiovascular Diseases & $45(16 \%)$ & $16(13 \%)$ & 0.3 \\
Neuro-psychiatric disorders & $47(17 \%)$ & $13(10 \%)$ & 0.09 \\
Cancer & $31(11 \%)$ & $16(13 \%)$ & 0.3 \\
Chronic Renal Insufficiency & $28(10 \%)$ & $15(12 \%)$ & 0.3 \\
Liver disorders & $123(44 \%)$ & $59(47 \%)$ & 0.3 \\
Others diseases & $4.6 \pm 3.2$ & $5.0 \pm 2.4$ & 0.2 \\
Number of Drugs & & & \\
& $9.6 \pm 5.8$ & $18 \pm 17$ & $<0.001$ \\
Days of Hospital stay & & $4.3 \pm 3.9$ & \\
Time of ADR from hospitalization- days & & & \\
\hline
\end{tabular}


Table 2: Description of Adverse Drug Reactions, leading or occurred during hospitalization.

\begin{tabular}{|c|c|c|}
\hline Event & $\begin{array}{l}\text { Number } \\
\text { of cases }\end{array}$ & Drug(number of cases) \\
\hline \multicolumn{3}{|l|}{ Gastrointestinal.-44(34\%) } \\
\hline Diarrhea & 28 & $\begin{array}{l}\text { Levofloxacin(17), ciprofloxacin(4), Amoxicilin/clavulanic(5), Ceftriaxone(1), } \\
\text { Piperacillin/Tazobactam(1), }\end{array}$ \\
\hline Pseudomenbranous colitis & 2 & Fosfomicine(1),Metformin(3),Chloroquin(1), colchicine(1),Levofloxacin(2) \\
\hline Nausea/vomits & 14 & Digoxin(4),Rifampin(1), Vibramycin(1),Ceftazidime(2), sildenafil(1) \\
\hline \multicolumn{3}{|l|}{ Hematological -17(13\%) } \\
\hline Bleeding, & 15 & Acenocumarol (11), Enoxaparin(4) \\
\hline Thrombocytopenia & 1 & Heparin (1) \\
\hline Pancytopenia & 1 & Ceftriaxone (1) \\
\hline \multicolumn{3}{|l|}{$\begin{array}{l}\text { Neurological and psychiatric- } \\
14(11 \%)\end{array}$} \\
\hline Oversedation & 3 & Fentanyl(1), tramadol(1), lorazepan(1) \\
\hline Altered mental status & 5 & Zolpidem(2), lorazepan(1), litium(1), levofloxacin(1). \\
\hline Dystonia /dyscinesias & 3 & Cleboprid(2)Levomepromazin(1) \\
\hline Hallucinations & 2 & Pregalabalin(1), codeín(1) \\
\hline Seizures & 1 & Imipenem(1) \\
\hline \multicolumn{3}{|l|}{ Skin and mucosa.- 18(14\%) } \\
\hline Rash & 9 & $\begin{array}{l}\text { Ceftriaxon(3), Piperacillin/Tazobactam(1), levofloxacin(1), Phenitoin(2), } \\
\text { atorvastatin(1),ciprofloxacin(1) }\end{array}$ \\
\hline Steven Johnson & 1 & Trimetoprim/sulfametoxazol(1) \\
\hline Muguet & 8 & Levofloxacin(4), meronem(1), budesonide(3) \\
\hline \multicolumn{3}{|l|}{ Hepatobiliary-8(6.2\%) } \\
\hline Hepatitis & 5 & Amoxicilin/clavulanic(2), dexketoprophen(1), ciprofloxacin(1), enoxaparin(1) \\
\hline Cholestasis & 3 & Salazopirin(1), etinilestradiol(1),rifampin(1) \\
\hline \multicolumn{3}{|l|}{ Cardiovascular- $7(5.5 \%)$} \\
\hline Bradychardia & 5 & $\operatorname{Digoxin}(5)$ \\
\hline Hypotension & 2 & Carvedilol(1), metamizol(1) \\
\hline Renal- 3(2.3\%) & & \\
\hline Renal dysfunction & 3 & Vancomicin(1), Iodure contrast(1), captopril(1) \\
\hline \multicolumn{3}{|l|}{ Electrolyte disorders $-8(6.2 \%)$} \\
\hline Hypokalemia & 4 & Hidroclorothiazid(4) \\
\hline Hyponatremia & 2 & Duloxetin(1), furosemid(1) \\
\hline Hyperkalemia & 2 & Spironolacton(2) \\
\hline \multicolumn{3}{|l|}{ Endocrine-3(2.3\%) } \\
\hline Hypoglycemia & 2 & Glibenclamid(2) \\
\hline Ginecomasty & 1 & Spironolacton(1) \\
\hline \multicolumn{3}{|l|}{ Respiratory-2(1.6\%) } \\
\hline Cough & 1 & Enalapril(1) \\
\hline Hipercapnic encephalopathy & 1 & Diazepan(1) \\
\hline \multicolumn{3}{|l|}{ Systemic-4(3.1\%) } \\
\hline Fever & 3 & Ceftazidime(1), ciprofloxacin(1),plasma(1) \\
\hline DRESS & 1 & Salazopirin(1) \\
\hline
\end{tabular}

DRESS: Drug Related Eosinophylia with Sistemic Symptoms 
Table 3: Differences in Patients with and without an Adverse Drug Reaction observed during hospitalization.

\begin{tabular}{|c|c|c|c|}
\hline & $\begin{array}{l}\text { CONTROL } \\
\mathbf{N}=\mathbf{2 7 9}\end{array}$ & $\begin{array}{l}\text { CASE } \\
\mathrm{N}=102\end{array}$ & p value \\
\hline Use of more 5 drugs & $173(62 \%)$ & $67(66 \%)$ & 0.38 \\
\hline \multicolumn{4}{|l|}{ Renal status at admission } \\
\hline Serum creatinine-mg/dL. & $1.11 \pm 0.57$ & $1.28 \pm 0.78$ & $<0.05$ \\
\hline EGFR - (ml/min $)$ & $70.3 \pm 31.8$ & $66.4 \pm 36.5$ & 0.31 \\
\hline \multirow{2}{*}{\multicolumn{4}{|c|}{$\begin{array}{l}\text { At ADR (case) or } \\
\text { higher during hospitalization (control) }\end{array}$}} \\
\hline & & & \\
\hline Serum creatinine-mg/dL. & $1.72 \pm 0.95$ & $2.02 \pm 1.22$ & $<0.05$ \\
\hline EGFR $<60 \mathrm{ml} / \mathrm{m}-(\%)$ & $61(22 \%)$ & $42(41 \%)$ & $<0.001$ \\
\hline Change EGFR vs previous $>20 \%-(\%)$ & $50(18 \%)$ & $36(35 \%)$ & $<0.001$ \\
\hline \multicolumn{4}{|l|}{ Liver status } \\
\hline Cirrhosis & $22(8 \%)$ & $12(12 \%)$ & 0.24 \\
\hline ALT-UI/ml & $73 \pm 43$ & $81 \pm 79$ & 0.21 \\
\hline FA- UI/ml & $94 \pm 64$ & $88 \pm 52$ & 0.39 \\
\hline Albumin $<3 \mathrm{mg} / \mathrm{dl}-(\%)$ & $59(21 \%)$ & $18(18 \%)$ & 0.45 \\
\hline \multicolumn{4}{|l|}{ Numb } \\
\hline 0 & $179(64 \%)$ & $16(16 \%)$ & $<0.0001$ \\
\hline Any & $100(36 \%)$ & $86(84 \%)$ & $<0.0001$ \\
\hline $1-3$ & $56(20 \%)$ & $50(49 \%)$ & $<0.0001$ \\
\hline$>3$ & $45(16 \%)$ & $36(35 \%)$ & $<0.001$ \\
\hline \multicolumn{4}{|l|}{ Medication use with interaction } \\
\hline Cytochrome P450 2C19 Inducer & $1(0.4 \%)$ & $2(1.9 \%)$ & 0.12 \\
\hline Inhibitors & $4(1.4 \%)$ & $2(1.9 \%)$ & 0.71 \\
\hline Substrates & $4(1.4 \%)$ & $3(2.9 \%)$ & 0.68 \\
\hline Cytochrome P450 2C9 & 0 & $1(0.9 \%)$ & 0.09 \\
\hline Inhibitors & $18(6.4 \%)$ & $14(13.7 \%)$ & $<0.05$ \\
\hline \multirow{2}{*}{ Cytochrome P450 3A4 $\begin{array}{c}\text { Substrates } \\
\text { Inducer }\end{array}$} & $13(4.7 \%)$ & $14(13.7 \%)$ & $<0.01$ \\
\hline & $1(0.4 \%)$ & $4(3.9 \%)$ & $<0.05$ \\
\hline Inhibitors & $7(2.5 \%)$ & $6(5.8 \%)$ & 0.11 \\
\hline \multirow{2}{*}{$\begin{array}{cc} & \text { Substrates } \\
\text { Cytochrome P450 2D6 } & \text { Inhibitors }\end{array}$} & $7(2.5 \%)$ & $10(9.8 \%)$ & 0.01 \\
\hline & $5(1.8 \%)$ & $5(4.9 \%)$ & 0.09 \\
\hline $\begin{array}{c}\text { Cytochrome P450 2D6 } \begin{array}{c}\text { Inhibitors } \\
\text { Substrates }\end{array} \\
\end{array}$ & $4(1.4 \%)$ & $5(4.9 \%)$ & $<0.05$ \\
\hline Cytochrome P450 1A2 Inhibitors & $1(0.4 \%)$ & $1(0.9 \%)$ & 0.46 \\
\hline Substrates & $2(0.7 \%)$ & $2(1.9 \%$ & 0.29 \\
\hline \multirow[t]{2}{*}{ Glycoprotein-P } & $2(0.7 \%)$ & $2(1.9 \%)$ & 0.29 \\
\hline & $1(0.4 \%)$ & $1(0.9 \%)$ & 0.46 \\
\hline Change EGFR $>20 \%$ or Drug interactions & $131(47 \%)$ & $90(88 \%)$ & $<0.0001$ \\
\hline
\end{tabular}


EGFR: Estimated glomerular filtration rate *: Grade $>\mathrm{C}$ denote interaction between drugs from a clinically significant manner to agents considered contraindicated (for more details see Methods)

Table 4: Logistic regression analysis with ADRs observed during hospitalization as dependent variable.

\begin{tabular}{|l|c|c|c|}
\hline & Odds ratio & 95\% CI & p value \\
\hline Male & 0.94 & $0.59-1.51$ & 0.81 \\
>70 years & 1.37 & $0.84-2.26$ & 0.21 \\
Treatment with more 5 drugs & 1.18 & $0.72-1.94$ & 0.51 \\
More 12-days hospitalization & 2.11 & $1.27-3.47$ & $<0.001$ \\
Albumin < 3 mg/dL & 1.22 & $0.74-2.05$ & 0.49 \\
Any drug interaction (Grade> C) & 9.33 & $5.12-17$ & $<0.0001$ \\
Change EFG <20\% over previous & 2.46 & $1.45-4.2$ & 0.001 \\
\end{tabular}

EGFR: Estimated glomerular filtration rate *: Grade $>$ C denote interaction between drugs from a clinically significant manner to agents considered contraindicated (for more details see Methods) 